\title{
Early Total Hip Arthroplasty for the Treatment of Acetabular Fractures
}

\author{
Michael C. Willey, MD ${ }^{1}$ Elizabeth Scott, MD ${ }^{1}$ J. Lawrence Marsh, MD ${ }^{1}$ \\ ${ }^{1}$ Department of Orthopaedic Surgery and Rehabilitation, University \\ of lowa Hospitals and Clinics, lowa City, lowa \\ Address for correspondence Michael C. Willey, MD, Department of \\ Orthopaedic Surgery and Rehabilitation, University of lowa Hospitals \\ and Clinics, 200 Hawkins Dr, lowa City, IA 52242 \\ J Hip Surg 2019;3:161-170. \\ (e-mail: michael-willey@uiowa.edu).
}

\begin{abstract}
Keywords

- acetabular fracture

- total hip arthroplasty

- management of acetabular fractures in the elderly

Early total hip arthroplasty in patients with acetabular fractures is considered in rare situations with specific indications. Generally, this treatment option is considered in patients older than 55 or 60 years, but the physiological age must also be considered. The patient should be functional and ambulatory before the injury and healthy enough to tolerate the insult of a surgical procedure of this magnitude. Preexisting conditions such as osteoporosis and osteoarthritis encourage consideration of total hip arthroplasty. Specific injury patterns are predictive of fixation failure in older patients with acetabular fractures. These findings represent worse articular injury and low bone density that would intuitively lead to failure. This "gull sign" or "seagull sign" describes either the central-superior dome impaction seen in high-transverse fractures or the impaction of the subchondral bone on the intact edge of a partial posterior column fracture. Other radiographic predictors of failure in posterior wall fractures include comminution of more than three fragments, involvement of the superior dome in high posterior wall fractures, and marginal impaction. Older patients have a high incidence of these radiographic findings, predictive of fixation failure without arthroplasty. Other injury characteristics including concomitant displaced femoral neck fracture and femoral head injury are also indications for total hip arthroplasty in older patients. Acute hip arthroplasty can be performed using the posterolateral, direct lateral, anterolateral, and anterior approaches to the hip. There are also reports of patients who underwent combined approaches to the hip for stabilization of the injury using the anterior intrapelvic approach and ilioinguinal approach. Combined approaches are generally not recommended. Extended approaches are not recommended or necessary for early arthroplasty in acetabular fractures. This review article highlights recent trends of early total hip arthroplasty in senior patients with acetabular fracture, and the indications for the procedure, complications, clinical outcomes, and technical considerations, with cases to highlight these concepts.
\end{abstract}

Operative fixation of displaced acetabular fractures with anatomical reduction has good reported outcomes in the

(1D) Michael Willey's ORCID is https://orcid.org/0000-0002-69228471.

(D)Elizabeth Scott's ORCID is https://orcid.org/0000-0003-12381931.

received

January 15, 2019

accepted after revision

April 4, 2019

published online

June 27, 2019 hands of experienced surgeons, but certain patient factors and injury patterns predictably lead to failure of reconstruction and posttraumatic osteoarthritis. ${ }^{1-3}$ As the elderly population increases and is more active, orthopaedic trauma surgeons treat more patients older than 60 years with displaced acetabular fractures. ${ }^{4,5}$ These patients more commonly have poor bone stock, preexisting osteoarthritis,

Copyright $\odot 2019$ by Thieme Medical Publishers, Inc., 333 Seventh Avenue, New York, NY 10001, USA.

DOI https://doi.org/ 10.1055/s-0039-1692199. Tel: +1(212) 584-4662. 
medical comorbidities, and fracture patterns that predictably lead to failure, ${ }^{5,6}$ complicating operative management of these injuries. Options to treat these injuries include nonoperative management, percutaneous fixation, open reduction internal fixation (ORIF), and ORIF with total hip arthroplasty (THA).

When modern THA was being developed, displaced acetabular fractures were often managed with traction/immobilization or less commonly with limited, open internal fixation. Series of patients with fracture-dislocations of the hip in the 1950s and 1960s treated with these techniques report "mild-to-moderate concessions."7 Patients with progressive loss of function were treated with cup arthroplasty or THA. Primary arthroplasty for acetabular fractures was not performed because "the magnitude of operative injury superimposed on the tissue injury from trauma has failed to improve what could be obtained by direct attack on the fracture."7 Around the same time, Coventry reported a series of five patients who underwent THA for chronic and subacute fracture-dislocations of the hip. ${ }^{8}$ Two patients underwent cemented THA at 3 and 7 weeks after the injury. Otherwise, THA was reserved for late reconstructions of chronically dislocated joints. Coventry described a technique of staged fixation of the acetabulum with removal of the femoral head and THA 5 to 8 weeks after the initial operation. One patient in this series had loosening of the acetabular component. ${ }^{8}$ Other studies reported a series of patients treated successfully with mold arthroplasty for acute acetabular fractures. ${ }^{9,10}$ Despite these reports of a small number of successful cases, early THA for acute acetabular fracture would not widely be considered until the development of the modern press-fit acetabular implant.

Most of the subsequent literature in the 1970s and 1980s focused on the late reconstruction of failed nonoperative or operative treatment of acetabular fractures with posttraumatic osteoarthritis and avascular necrosis of the femoral head. Boardman and Charnley reported the largest series at the time of patients who underwent late reconstruction of a failed acetabular fracture with THA. ${ }^{11}$ Their average time from injury to reconstruction was 15 years. Most of these patients were initially treated nonoperatively $(81 \%) .{ }^{11}$ These patients were relatively young at the time of reconstruction (54.7 years), and they reported good outcomes with low complication rates. More recent series using press-fit acetabular components report improved functional outcomes for these patients but higher rates of revision surgery at midterm follow-up compared with patients with primary osteoarthritis. Ranawat et al reported a revision rate of $19 \%$ at an average of 4.7 years follow-up for various indications including infection, aseptic loosening, and dislocation. ${ }^{12}$ Berry and Halasy reported a series of 33 patients with late THA for failed acetabular fracture with minimum 10 years follow-up. ${ }^{13}$ Reconstruction was performed for failed ORIF in $44 \%$ of cases. Overall, there was a $41 \%$ revision rate. Nine $(27 \%)$ hips underwent revision of the acetabular component. Higher rates of revision surgery in these series compared with patients with primary osteoarthritis allude to the technical difficulty of these late reconstructions even when performed by experi- enced surgeons and the relatively young age of the patients with increased demand on implants.

In the 1990s, reports of a larger series of patients who underwent successful THA for acute acetabular fracture brought this treatment option to the forefront. Since that time multiple authors have published a series of cases with varying rates of success, but overall reliable outcomes for appropriate indications. Mears and Shirahama published descriptions of the technical aspects of the procedure ${ }^{14}$ and later the largest series of patients treated with acute THA for acetabular fracture. ${ }^{15}$ The following discusses the indications for early THA in patients with acetabular fracture, clinical outcomes, and technical considerations. Three case examples are included to highlight technical considerations.

\section{Indications for Early Total Hip Arthroplasty in Patients with Acetabular Fractures}

Early THA is considered in a small subset of patients with acetabular fractures. Most patients with displaced acetabular fractures are indicated for ORIF, and multiple surgical approaches have been described. For experienced surgeons, satisfactory clinical outcomes have been reliably achieved. ${ }^{1,16,17}$

Patients who are physiologically and chronologically older offer more complexity for the treating surgeon. In senior patients (older than 60 years), rates of conversion to late THA for failed fixation has been shown to be between $6^{16}$ and $28 \%{ }^{3}$ These patients have higher rates of fracture patterns that predictably lead to a failure of fixation. ${ }^{5}$ Ferguson et al reported that patients older than 60 years have roof impaction in $40 \%$ of cases of anterior column fractures and marginal impaction in $38 \%$ of posterior wall fractures. ${ }^{5}$ In these older patients, the treating surgeon needs to be able to recognize fracture patterns that will predictably lead to a failure of operative fixation to appropriately indicate early THA.

Posterior wall fractures, isolated and with associated fracture patterns, have rates of failure after operative fixation between $10^{18}$ and $26 \%{ }^{2}$ depending on the severity of the initial injury and how the author describes failure. Predictors of failure include comminution of more than three fragments, involvement of the superior dome, and marginal impaction. ${ }^{2,18}$ Moed et al also found poor results in patients who developed osteonecrosis of the femoral head. Osteonecrosis seen more commonly in patients with greater than 12 hours to closed reduction of a hip dislocation. In older patients with these predictors of failure with ORIF after posterior wall fracture, THA can be considered as a viable treatment option.

In patients older than 60 years, the presence of dome impaction has been shown to be predictive of fixation failure. This is referred to as the "seagull sign" or "gull sign" and is described based on two different fracture patterns. Judet et al described a partial fracture of the posterior column, where the intact posterior column at the articular surface was impacted by the femoral head. ${ }^{19}$ This impaction can often be addressed through a posterior approach but is an indicator of osteoporotic bone. Anglen et al in an often-quoted study reported outcomes in a series of patients older than 
60 years with fixation of acetabular fracture. They noted that patients with central-superior dome impaction in a hightransverse fracture pattern and central dislocation had a high failure rate. ${ }^{6}$ Eighty percent of patients with this radiographic finding did not have anatomical reduction with fixation, and the rate of loss of reduction was high. These impaction injuries indicate more severe articular injury as well as low subchondral bone density, both predictors of failure. They concluded in their paper that THA should be considered in senior patients with a "gull sign."

Most papers that report a series of patients undergoing early THA for acetabular fractures report similar indications for the operation. ${ }^{15,16,20-23}$ Elderly patients are a common justification for THA. Generally, a cutoff of 60 years is described, but the physiological age of the patient must be considered. Carroll et al included a useful flowchart to consider when managing senior patients with acetabular fracture. ${ }^{22}$ THA was considered when an elderly patient was determined to be able to tolerate surgery, was functional and ambulatory before the injury, and fit the criteria of irreducible fracture, longer planned operation with ORIF only, impaction of the articular surface, displaced femoral neck fracture or femoral head fracture, arthrosis, and severe osteoporosis. ${ }^{22}$ Similar inclusion criteria are listed in these series.

\section{Clinical Outcomes for Total Hip Arthroplasty in Acute Acetabular Fractures}

Clinical concerns for performing early combined ORIF with THA in patients with acetabular fracture include the magnitude of the operation in elderly patients who are injured and often polytraumatized with preexisting comorbidities, loosening of the acetabular component due to compromised fixation, and dislocation. Overall, reported series of these operations using modern implants and techniques have low complication rates with good function, but complications and reoperation rate are slightly higher than that in patients undergoing THA for osteoarthritis.

Mears and Velyvis reported the largest, most complete series on our literature review. ${ }^{15}$ They reported on 57 patients who underwent early THA combined with ORIF for acetabular fracture, with an average follow-up of 8.7 years. The most common complication they reported was heterotopic ossification in $11 \%$. There were no deep infections or mortality related to the surgery. There was mild settling of the acetabular component early ( $3 \mathrm{~mm}$ medially and $2 \mathrm{~mm}$ vertically), and no patients suffered nonunion of the fracture or loosening of the acetabular component. Other series also reported settling of the acetabular component. ${ }^{20}$ Six patients had excessive medialization of the acetabular cup, as determined by the surgeon, but this was not associated with loosening or pain. There were only two dislocations in the series. One required revision for recurrent dislocations. Multiple series reported a low rate of dislocation. Herscovici et al in a series of 22 patients undergoing the combined procedure reported on two patients who underwent revision for dislocation. ${ }^{21}$ In their series, two patients also underwent revision for component loosening. Heterotopic ossification is a common finding in these patients postoperatively. They reported a rate of $21 \%$. Only one patient has grade IV ossification and none elected to have a repeat operation for the heterotopic ossification. Complication rates of early THA for acetabular fracture are summarized in - Table $\mathbf{1}$.

It should be noted that regardless of timing, THA performed after acetabular fracture demonstrates decreased survivorship and higher complication rates compared with THA performed for primary osteoarthritis or avascular necrosis. Morison et al reports 64 to $78 \%$ survival rate at 10 years compared with $90 \%$ in hips without previous acetabular fracture in a matched cohort study. ${ }^{24}$

It should also be noted that the surgeons reporting success with this operation all perform a high volume of THA and fixation of acetabular fracture and have teams that are

Table 1 Complication rates reported in a series of early THA for acetabular fracture

\begin{tabular}{|c|c|c|c|c|c|c|c|c|}
\hline Author & $\begin{array}{l}\text { Number } \\
\text { of } \\
\text { patients }\end{array}$ & $\begin{array}{l}\text { Revision at } \\
\text { follow-up } \\
\text { (\%) }\end{array}$ & $\begin{array}{l}\text { Heterotopic } \\
\text { ossification } \\
(\%)\end{array}$ & $\begin{array}{l}\text { Acetabular } \\
\text { loosing } \\
\text { (\%) }\end{array}$ & $\begin{array}{l}\text { Femoral } \\
\text { loosening } \\
(\%)\end{array}$ & $\begin{array}{l}\text { Dislocation } \\
\text { (requiring } \\
\text { revision) } \\
(\%)\end{array}$ & $\begin{array}{l}\text { Infection } \\
(\%)\end{array}$ & $\begin{array}{l}\text { Early } \\
\text { postoperatively } \\
\text { mortality (\%) }\end{array}$ \\
\hline $\begin{array}{l}\text { Mears and } \\
\text { Velyvis }{ }^{15}\end{array}$ & 57 & 5.3 & 11 & 0 & 0 & $3.5(1.8)$ & 0 & 0 \\
\hline Herscovici et al ${ }^{21}$ & 22 & 18.2 & 22.7 & 9 & 9 & $13.6(9)$ & 0 & 0 \\
\hline Beaulé et al ${ }^{25}$ & 10 & 0 & 10 & 0 & 0 & $10(0)$ & 0 & 0 \\
\hline Mouhsine et al ${ }^{30}$ & 11 & 0 & 27.3 & 0 & 0 & 0 & 0 & 0 \\
\hline Boraiah et $\mathrm{al}^{20}$ & 18 & 5.6 & 5.6 & 5.6 & 5.6 & 5.6 & 5.6 & 0 \\
\hline Rickman et $a^{27}$ & 24 & 0 & 0 & 0 & 0 & 0 & 4.2 & 4.2 \\
\hline Sermon et al $^{28}$ & 64 & 8 & 28 & - & - & - & - & - \\
\hline $\begin{array}{l}\text { Enocson and } \\
\text { Blomfeldtet } \mathrm{al}^{26}\end{array}$ & 15 & 0 & 26.7 & 0 & 0 & 0 & 0 & 7 \\
\hline Lin et $a^{17}$ & 33 & 6 & 27.2 & 3 & 0 & 3 & 3 & 0 \\
\hline Total & 254 & 5.9 & 18.5 & 1.6 & 2 & 4.3 & 1.5 & 1.1 \\
\hline
\end{tabular}

Abbreviation: THA, total hip arthroplasty. 
prepared for the magnitude of the operation and its possible complications.

\section{Technical Considerations}

Early THA has been described using multiple approaches to the hip. Mears et al reported using three different approaches for the reconstruction and arthroplasty depending on the pattern of the fracture, but they highlighted the advantage of prepping the acetabulum through the anterolateral approach. In their series, the posterolateral approach was used in $28 \%$, anterolateral in $67 \%$, and extended lateral in $5 \%{ }^{15}$ They also published the most detailed description of the technical aspects of the operation. Their preferred approach was the anterolateral approach because this allowed for reaming and positioning of the acetabulum without pressure from the anterior soft tissues to misdirect into a retroverted position. The components are placed in the axis of the acetabulum. The resected femoral head is used as a structural bone graft. A multihole press-fit acetabular component allows for the placement of multiple $6.5-\mathrm{mm}$ screws and uses the cup as a "hemispherical plate" to support the fixation.

Herscovici et al reported using an ilioinguinal approach combined with a posterolateral approach in three patients. ${ }^{21}$ The indication was the concern that fixation through a posterolateral approach would not sufficiently stabilize the pelvis to support the acetabular component. The pelvis was reduced and stabilized through the ilioinguinal approach with the patient supine and then positioned lateral to perform posterior fixation and THA. Dual approaches were not preferred because of longer operative times and increased blood loss.

Beaulé et al reported the use of an anterior Levine approach for the fixation of an acetabular fracture with anterior THA. ${ }^{25}$ This series primarily included anterior column/wall fractures that were best reduced and stabilized through this approach. Series published by Boraiah et $\mathrm{al}^{20}$ as well as Enocson and Blomfeldt ${ }^{26}$ used only the posterolateral approach. Rickman et al primarily used an anterior intrapelvic approach combined with a posterolateral approach for THA. ${ }^{27}$ They advocated that their fixation was safe for early weight-bearing with THA. Surgeons should use approaches that they perform often and allow for stable fixation before arthroplasty.

Cable fixation is also described for the fixation of these injuries. $^{14,28}$ There are reports of safe placement of these fixation devices that allow for the stabilization of the injury to allow for THA. This should not be performed without extensive previous technical experience with this fixation strategy.

\section{Case Examples and Authors' Preferred Management}

In our practice, early THA for patients with acetabular fracture is uncommon but is strongly considered in older patients with fracture patterns that will predictably lead to failure with ORIF alone. Previous studies at our institution have highlighted patterns with high failure rates, and this is taken into consideration when managing these patients. ${ }^{2} \mathrm{~A}$ review of our patients with operatively treated acetabular fractures identified 14 patients who underwent early THA. During this time period, 215 patients underwent operative fixation without arthroplasty. Early THA was performed acutely in $6.5 \%$ of cases with reliable results. Elderly patients with displaced both-column, anterior column, and anterior column fractures that could be mobilized early were treated nonoperatively.

In the evaluation of these patients, the preinjury ambulatory/functional status, preexisting comorbidities, and associated injuries must be carefully considered. As shown in the previously described series, these patients often offer more complexity in the form of preexisting conditions. A similar medical and trauma work-up is performed in patients who have displaced femoral neck fractures in this age group.

Standard work-up in patients with acetabular fracture includes an anteroposterior (AP) pelvis and Judet oblique films taken in the emergency room. Computed tomography (CT) scan is used to assess articular injury and further evaluate fracture pattern. Three-dimensional reconstructions are useful for preoperative planning. After a patient is indicated for early THA, a low AP pelvis radiograph is obtained for templating.

Our patients all undergo screening for Staphylococcus aureus (SA) nasal colonization preoperatively. Patients who are positive for SA colonization are given mupirocin nasal ointment and chlorhexidine washes twice a day for 5 days. Surgery is not delayed for completion of this treatment. Positive screening for methicillin-resistant SA is an indication to add vancomycin to the perioperative antibiotics. Ancef is given to all patients before incision in the operating room. There is evidence that gram-negative coverage should be added to the perioperative antibiotics in patients who are undergoing pelvis surgery, ${ }^{29}$ but this is not currently performed in our practice. Enoxaparin or subcutaneous heparin is given, except for the day of surgery, unless contraindicated for deep venous thrombosis prophylaxis.

The indications for early THA in our practice are similar to the previously presented series. Age above 55 or 60 years is often used arbitrarily as an age when arthroplasty should be considered as one of the treatment options, but the physiological age of the patient should be considered, as well as the opinion of the surgeon for the chances of success with open reduction and internal fixation alone. THA can be considered in younger patients with certain failure using standard fixation strategies. Certainly, severe articular comminution or impaction is a predictor of failure as well as significant femoral head injury/fracture. Preexisting osteoarthritis would push toward THA. Osteoporosis is also taken into consideration. In specific patients, the decision to proceed with THA is made intraoperatively after evaluation of the severity of articular injury. This possibility must be discussed with the patient preoperatively.

In patients with comminuted posterior wall fractures indicated for THA, the cup is placed more medially. This allows for more surface area with press-fit fixation on the 

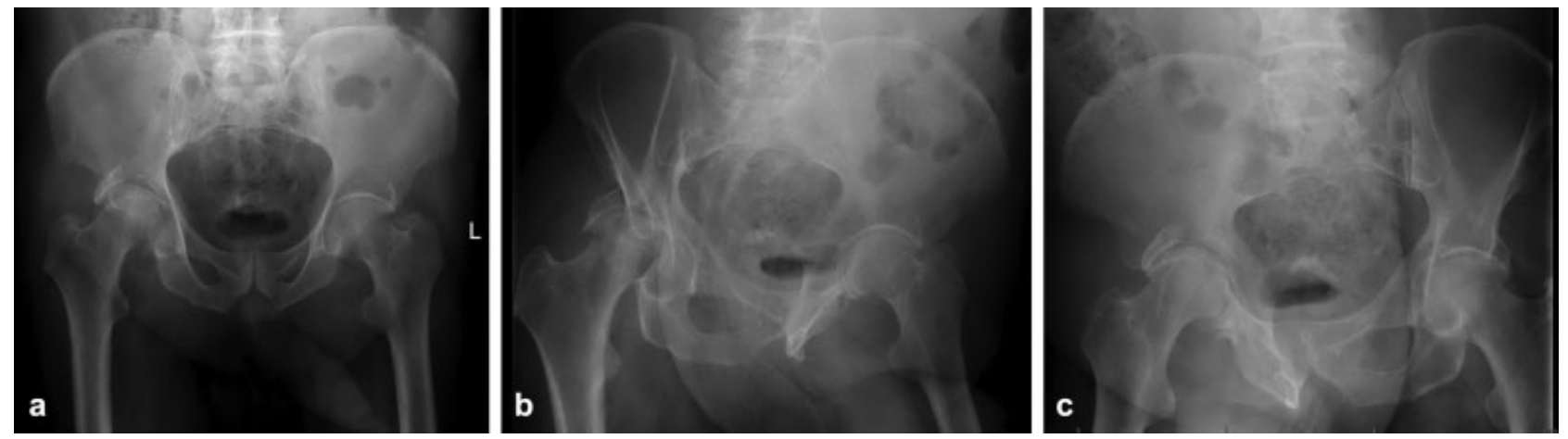

Fig. $1(\mathbf{a}-\mathbf{c})$ Anteroposterior pelvis and Judet oblique views of the patient presented in case 1.

intact posterior wall and posterior column. In anterior column fractures with bone defects, the femoral head is morselized or used as a structural graft to support the acetabular component. Also, the femoral head is osteotomized prior to fixation to allow for easier reduction and exposure of the acetabulum.

Posterolateral approach is our preferred approach for fixation of the fracture and THA. Extended approaches or dual approaches add significant risk, as shown in other series, ${ }^{21}$ and is not required to obtain stability of the pelvis with modern press-fit acetabular components. Multihole acetabular components are used to allow for fixation across the facture and for added stability. In anterior fracture patterns, a portion of the femoral head is occasionally placed in anterior defects either as a structural or morselized graft. The cup is secured to the posterior column. In our experience, adequate stability can be obtained through this approach. In the absence of severe osteoporosis, uncemented femoral components are preferred.

\section{Case 1}

A 68-year-old man with a past medical history of hypertension suffered a 12-feet fall from a ladder, resulting in a posterior wall acetabular fracture-dislocation. He had no
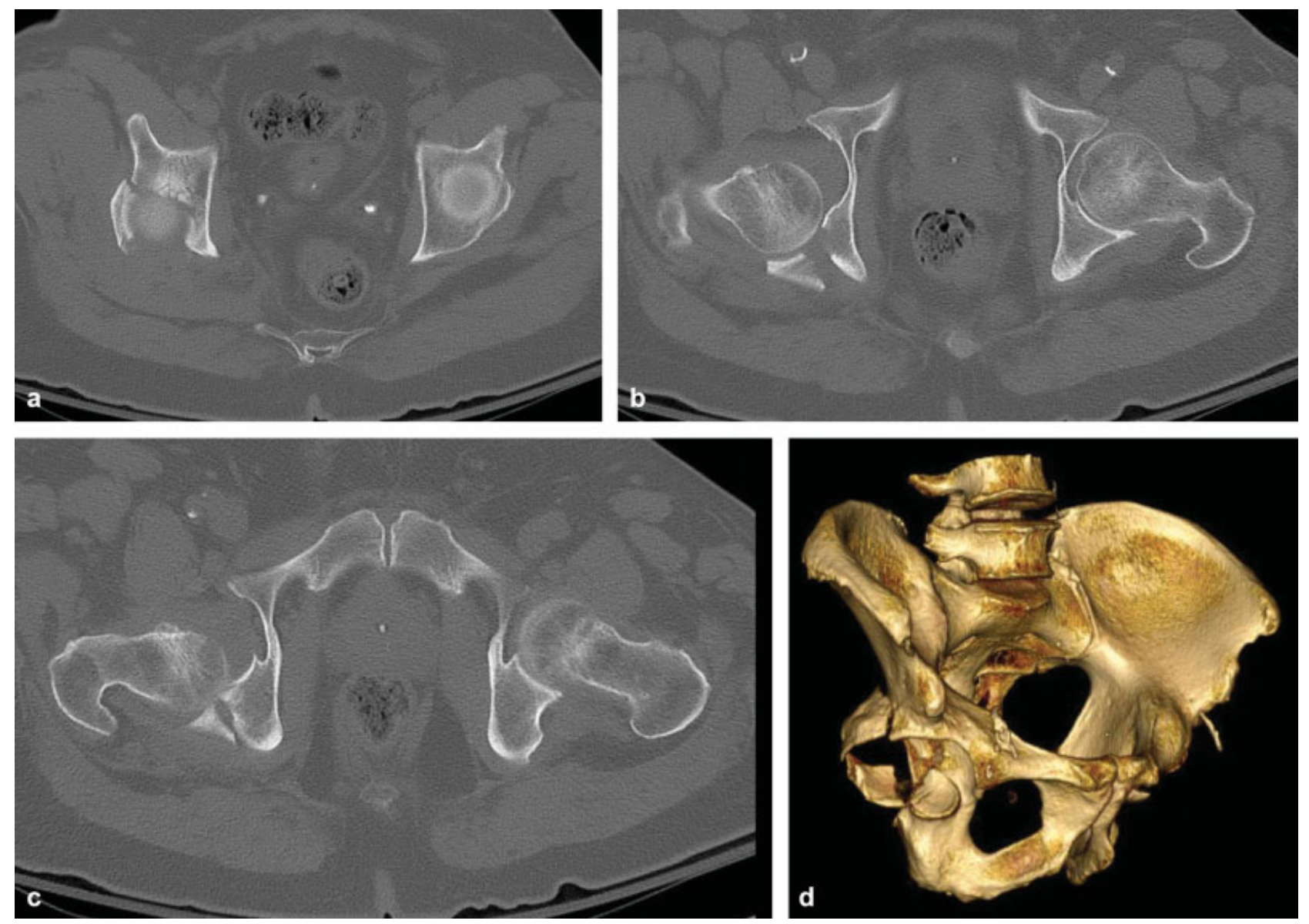

Fig. 2 (a-d) Computed tomography (CT) scan with three-dimensional reconstruction of the patient presented in case 1. 
other injuries. Prior to the injury, he worked in a factory. He had no prior history of hip pain.

Radiographs and CT scan demonstrated a comminuted posterior wall acetabular fracture with marginal impaction (-Figs. 1 and 2). He was evaluated by the general surgery trauma service as well as medical teams. After a discussion with him regarding the prognosis of the injury and potential treatment options, he underwent open reduction and internal fixation with THA. A standard posterolateral approach was performed. The femoral neck osteotomy was performed and the femoral head was removed. The intact acetabulum was reamed to $1 \mathrm{~mm}$ less than the selected implant. The
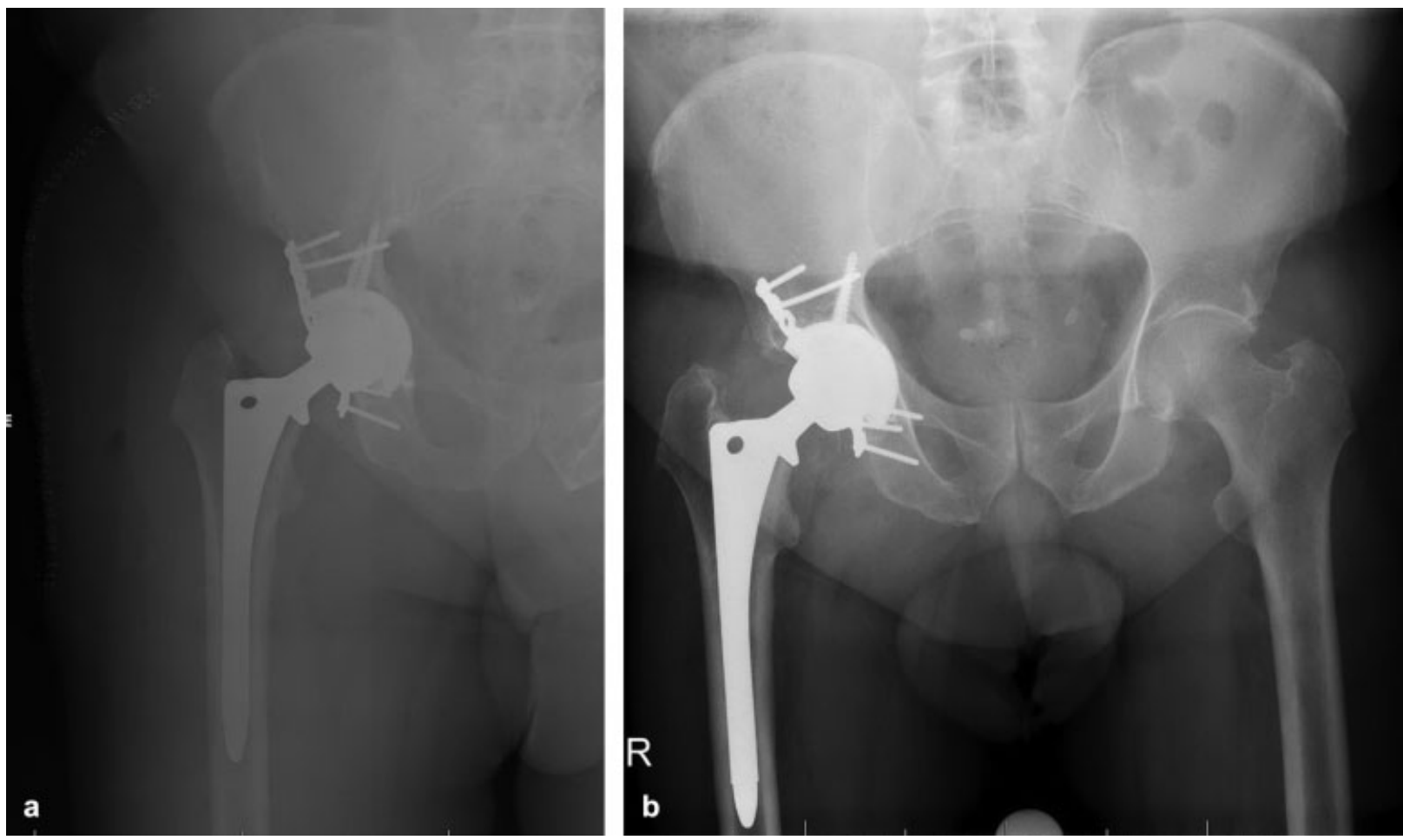

Fig. 3 (a-b) Immediate postoperative and 9-month radiographs after reconstruction in case 1.
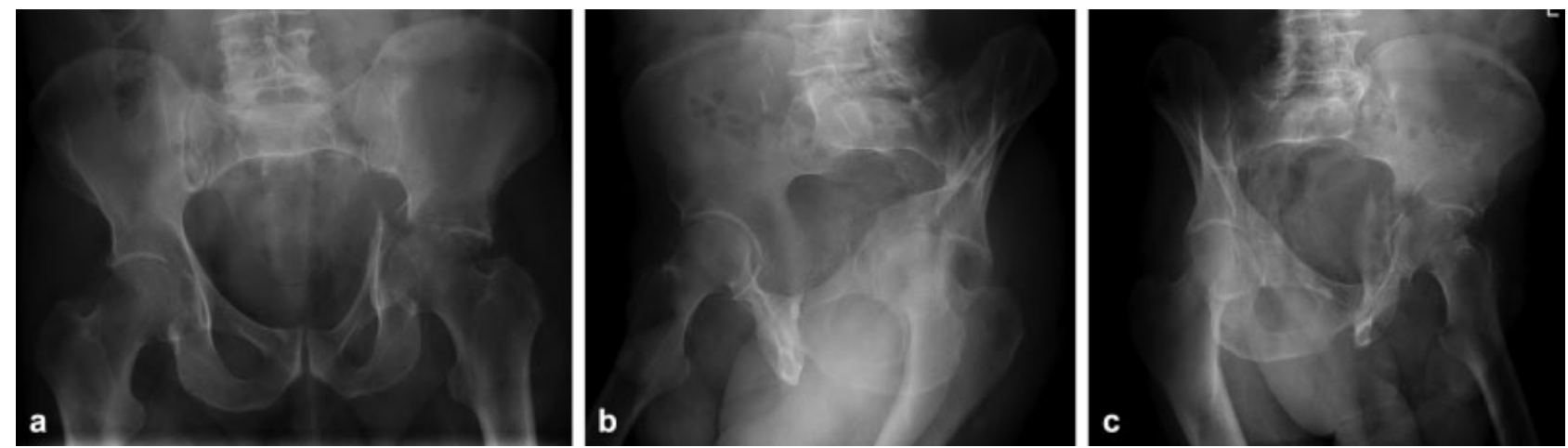

Fig. $4(a-c)$ Anteroposterior pelvis and Judet oblique views of the patient presented in case 2.
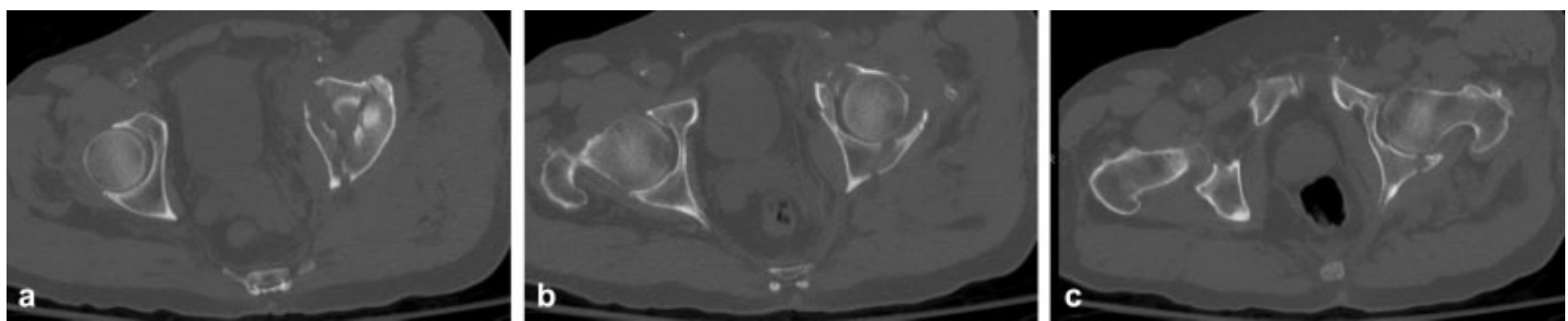

Fig. $5(\mathbf{a}-\mathbf{c})$ Computed tomography (CT) scan of the patient presented in case 2. 
posterior wall fragments were then reduced to the trial acetabulum and fixed using standard techniques for a posterior wall fracture using a nine-hole pelvic reconstruction plate. A standard three-hole acetabular component was used as we had adequate fixation and did not require a multihole cup. The femoral component was placed using standard techniques.

The patient did well postoperatively. He was last seen in clinic 9 months after the procedure and was having no pain. Postoperative radiographs are shown in - Fig. 3.

\section{Case 2}

A 79-year-old man with a history of hypertension suffered a 5-feet fall from a ladder resulting in a transverse posterior wall acetabular fracture with central dislocation. He had retired and previously worked as an engineer. He had no previous hip pain or injuries.

Radiographs and CT scan demonstrated a transverse posterior wall fracture with articular comminution (-Figs. 4 and 5). In this case, the "gull sign" can be seen on both AP and obturator oblique radiographs, indicating an
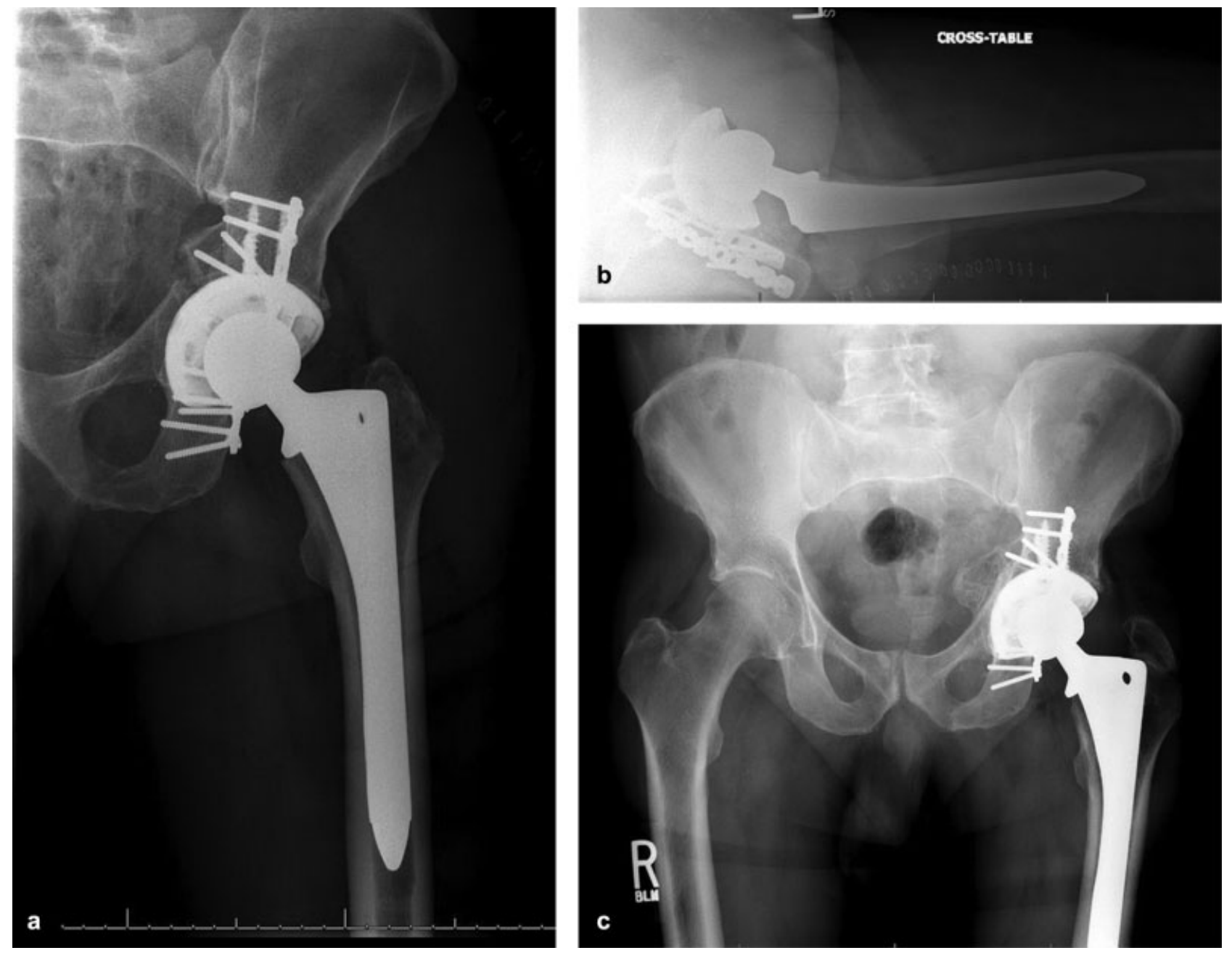

Fig. 6 (a-c) Immediate postoperative and 5-year radiographs after reconstruction in case 2.
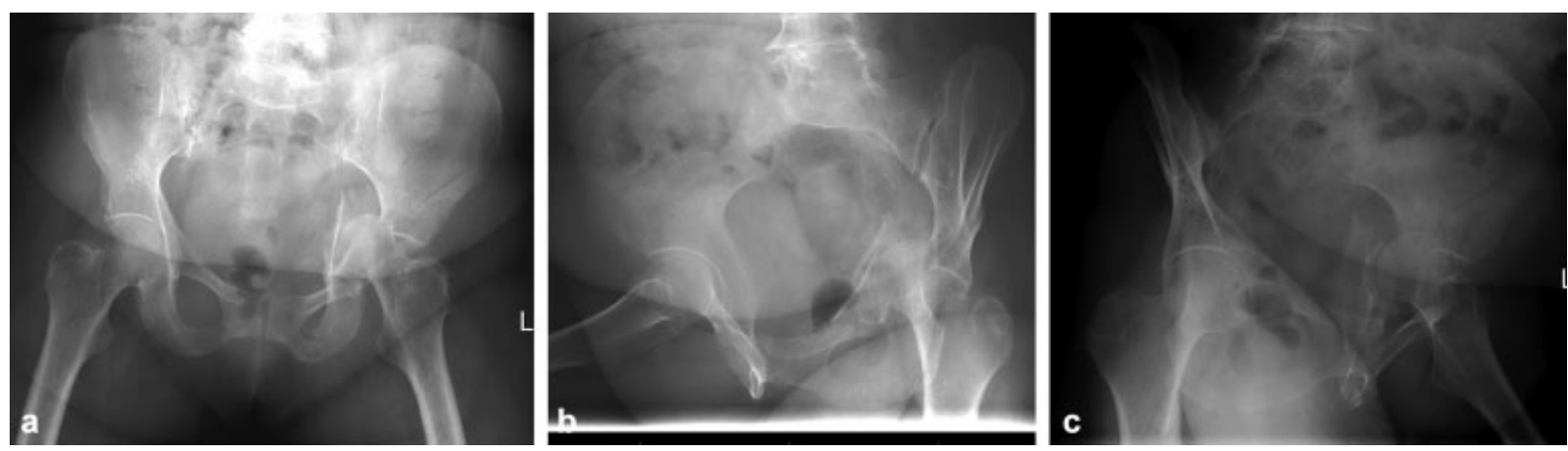

Fig. $7(a-c)$ Anteroposterior pelvis and Judet oblique views of the patient presented in case 3. 
articular injury predictive of failure with operative fixation alone. He is also noted to have joint space narrowing on the contralateral hip indicating preexisting osteoarthritis. He was indicated for ORIF with THA. He was taken to the operating room 4 days after the injury. Again, a standard posterolateral approach was performed. In this case, the transverse fracture was reduced after dislocation and removal of the femoral head. Fixation was performed with a nine-hole pelvic reconstruction plate and a $1 / 3$ tubular plate. After fixation, reaming of the acetabulum was performed. Standard THA was performed with a multihole acetabular component.

The patient did well postoperatively. He was last seen in clinic 5 years after the procedure and was having no pain. Follow-up radiographs are shown in - Fig. 6. He was very active and continued to push mow his lawn and do yard work.

\section{Case 3}

A 62-year-old woman with a past medical history of osteogenesis imperfecta suffered a fall from standing in the bathroom, resulting in a both-column acetabular fracture with central dislocation. She also had a distal radius fracture but no other injuries. She was otherwise healthy and had no preexisting hip pain.

Radiographs and CT scan demonstrated a both-column acetabular fracture with articular comminution and central dislocation (-Figs. 7 and 8). Again, in this case, the "gull sign" is seen on radiographs. Her case had added complexity due to her osteogenesis imperfecta. She was indicated for ORIF with THA and taken to the operating room 4 days after the injury. The posterolateral approach was performed. The acetabulum was reduced using standard techniques and stabilized using three pelvic reconstruction plates. Despite her soft bone due to osteogenesis imperfecta stable fixation was achieved. The acetabulum was reamed and a multihole cup was placed. Standard press-fit femoral arthroplasty was performed.

This case was significantly more difficult because of low bone density. At the 2-year follow-up, the cup migrated medially compared with initial postoperative radiographs (-Fig. 9). The implants were stable at follow-up, and the patient had some posterior pain with increased activities but otherwise was doing well.
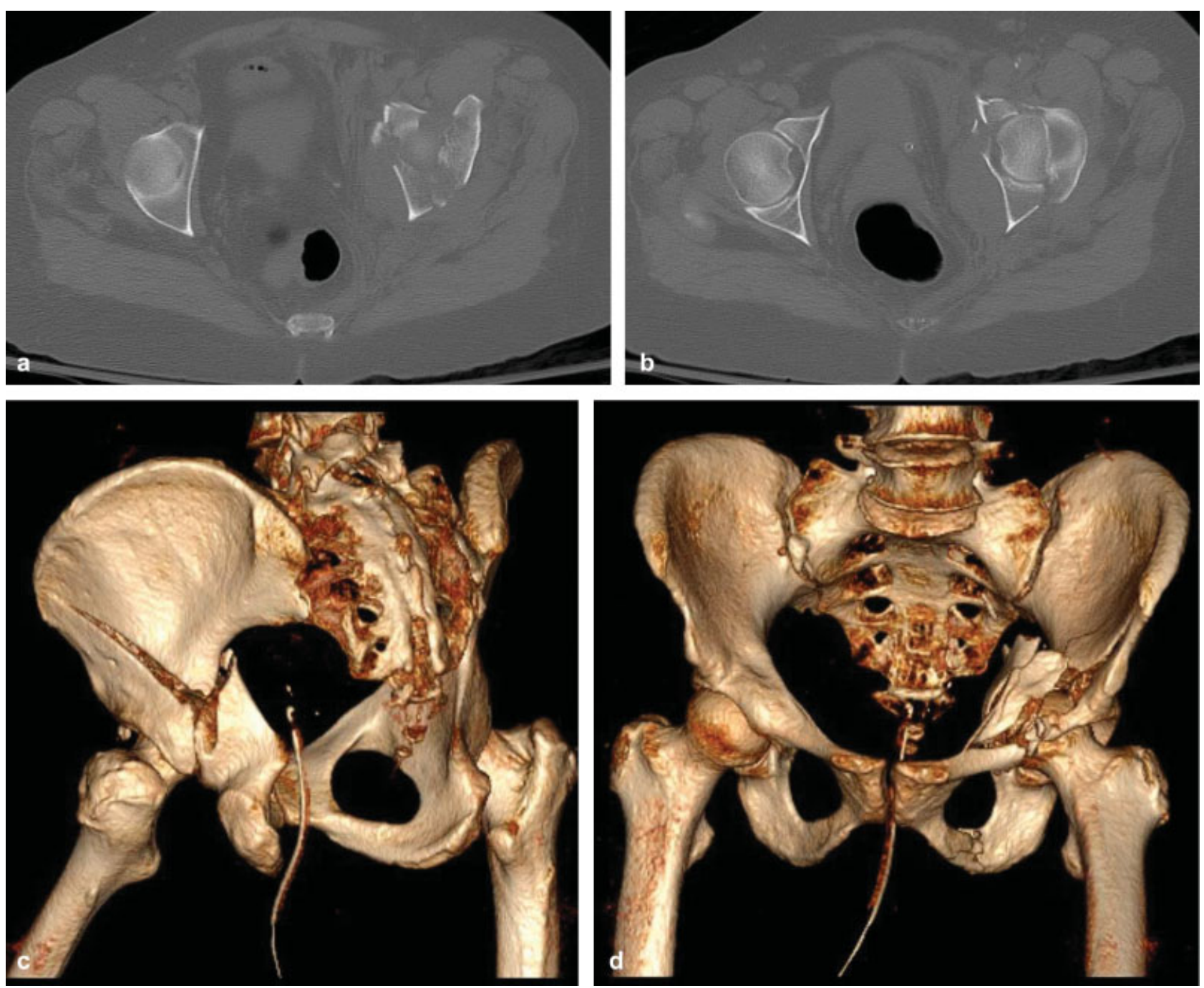

Fig. 8 (a-d) Computed tomography (CT) scan with three-dimensional reconstruction of the patient presented in case 3. 

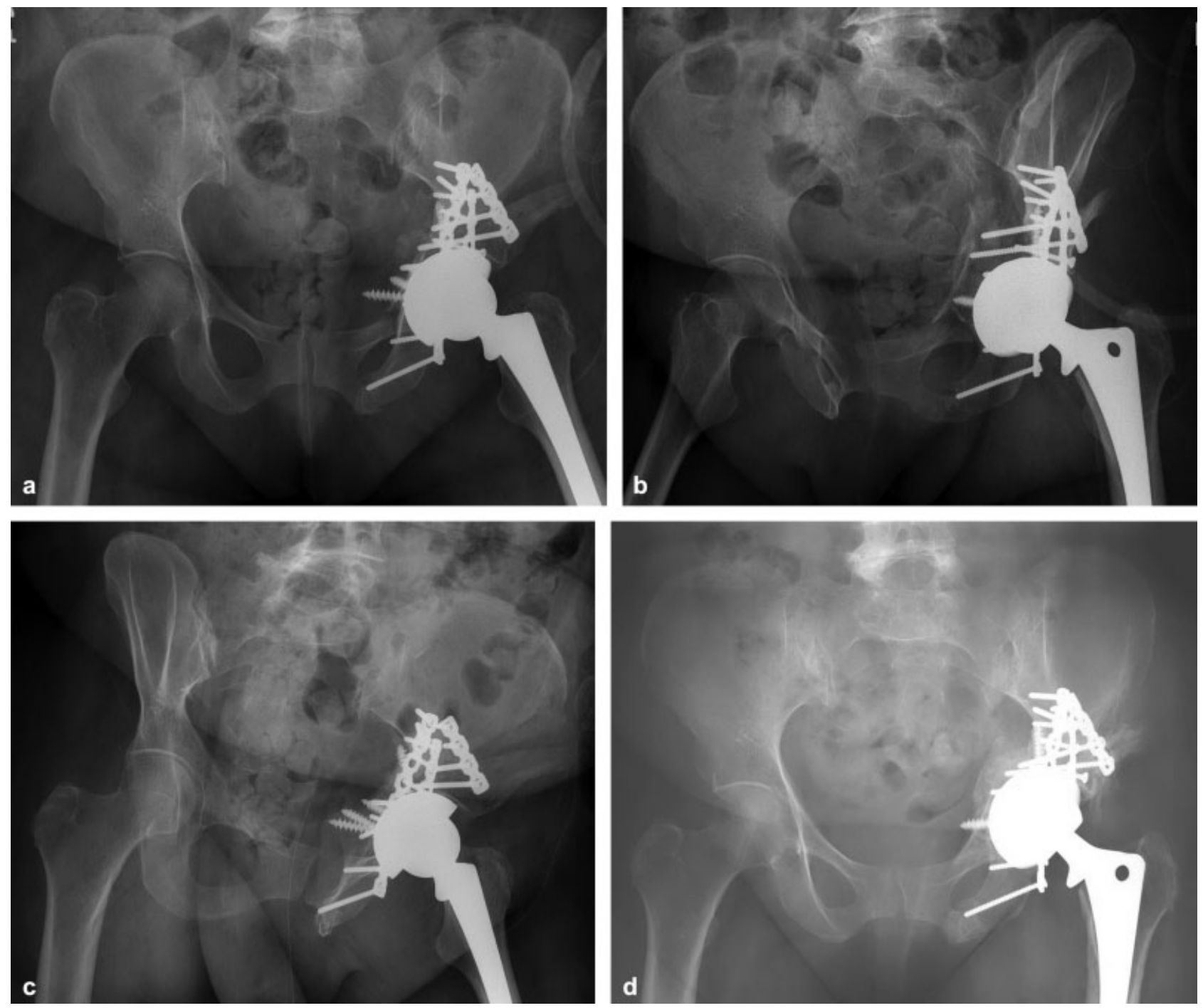

Fig. 9 (a-d) Immediate postoperative and 2-year radiographs after reconstruction in case 3.

\section{Disclosure}

The authors have nothing to disclose related to this paper.

\section{Conflicts of Interest}

None declared.

\section{References}

1 Tannast M, Najibi S, Matta JM. Two to twenty-year survivorship of the hip in 810 patients with operatively treated acetabular fractures. J Bone Joint Surg Am 2012;94(17):1559-1567

2 Saterbak AM, Marsh JL, Nepola JV, Brandser EA, Turbett T. Clinical failure after posterior wall acetabular fractures: the influence of initial fracture patterns. J Orthop Trauma 2000;14(04):230-237

3 O'Toole RV, Hui E, Chandra A, Nascone JW. How often does open reduction and internal fixation of geriatric acetabular fractures lead to hip arthroplasty? J Orthop Trauma 2014;28(03):148-153

4 Mears DC. Surgical treatment of acetabular fractures in elderly patients with osteoporotic bone. J Am Acad Orthop Surg 1999;7 (02):128-141

5 Ferguson TA, Patel R, Bhandari M, Matta JM. Fractures of the acetabulum in patients aged 60 years and older: an epidemiological and radiological study. J Bone Joint Surg Br 2010;92(02):250-257
6 Anglen JO, Burd TA, Hendricks KJ, Harrison P. The "Gull Sign": a harbinger of failure for internal fixation of geriatric acetabular fractures. J Orthop Trauma 2003;17(09):625-634

7 Larson CB. Fracture dislocations of the hip. Clin Orthop Relat Res 1973;(92):147-154

8 Coventry MB. The treatment of fracture-dislocation of the hip by total hip arthroplasty.J Bone Joint Surg Am 1974;56(06):1128-1134

9 Kelly PJ, Lipscomb PR. Primary vitallium-mold arthroplasty for posterior dislocation of the hip with fracture of the femoral head. J Bone Joint Surg Am 1958;40-A(03):675-680

10 Westerborn A. Central dislocation of the femoral head treated with mold arthroplasty. J Bone Joint Surg Am 1954;36(A:2):307-314

11 Boardman KP, Charnley J. Low-friction arthroplasty after fracturedislocations of the hip. J Bone Joint Surg $\mathrm{Br} 1978 ; 60-\mathrm{B}(04)$ : 495-497

12 Ranawat A, Zelken J, Helfet D, Buly R. Total hip arthroplasty for posttraumatic arthritis after acetabular fracture. J Arthroplasty 2009;24(05):759-767

13 Berry DJ, Halasy M. Uncemented acetabular components for arthritis after acetabular fracture. Clin Orthop Relat Res 2002; (405):164-167

14 Mears DC, Shirahama M. Stabilization of an acetabular fracture with cables for acute total hip arthroplasty. J Arthroplasty 1998; 13(01):104-107 
15 Mears DC, Velyvis JH. Acute total hip arthroplasty for selected displaced acetabular fractures: two to twelve-year results. J Bone Joint Surg Am 2002;84-A(01):1-9

16 Helfet DL, Borrelli J Jr, DiPasquale T, Sanders R. Stabilization of acetabular fractures in elderly patients. J Bone Joint Surg Am 1992;74(05):753-765

17 Lin C, Caron J, Schmidt AH, Torchia M, Templeman D. Functional outcomes after total hip arthroplasty for the acute management of acetabular fractures: 1- to 14-year follow-up. J Orthop Trauma 2015;29(03):151-159

18 Moed BR, WillsonCarr SE, Watson JT. Results of operative treatment of fractures of the posterior wall of the acetabulum. J Bone Joint Surg Am 2002;84-A(05):752-758

19 Judet R, Judet J, Lanzetta A, Letournel E. Fractures of the acetabulum. Classification and guiding rules for open reduction [in Italian]. Arch Ortop 1968;81(03):119-158

20 Boraiah S, Ragsdale M, Achor T, Zelicof S, Asprinio DE. Open reduction internal fixation and primary total hip arthroplasty of selected acetabular fractures. J Orthop Trauma 2009;23(04):243-248

21 Herscovici D Jr, Lindvall E, Bolhofner B, Scaduto JM. The combined hip procedure: open reduction internal fixation combined with total hip arthroplasty for the management of acetabular fractures in the elderly. J Orthop Trauma 2010;24(05):291-296

22 Carroll EA, Huber FG, Goldman AT, et al. Treatment of acetabular fractures in an older population. J Orthop Trauma 2010;24(10): 637-644
23 Scott CEH, MacDonald D, Moran M, White TO, Patton JT, Keating JF. Cemented total hip arthroplasty following acetabular fracture. Bone Joint J 2017;99-B(10):1399-1408

24 Morison Z, Moojen DJ, Nauth A, et al. Total hip arthroplasty after acetabular fracture is associated with lower survivorship and more complications. Clin Orthop Relat Res 2016;474(02):392-398

25 Beaulé PE, Griffin DB, Matta JM. The Levine anterior approach for total hip replacement as the treatment for an acute acetabular fracture. J Orthop Trauma 2004;18(09):623-629

26 Enocson A, Blomfeldt R. Acetabular fractures in the elderly treated with a primary Burch-Schneider reinforcement ring, autologous bone graft, and a total hip arthroplasty: a prospective study with a 4-year follow-up. J Orthop Trauma 2014;28(06):330-337

27 Rickman M, Young J, Trompeter A, Pearce R, Hamilton M. Managing acetabular fractures in the elderly with fixation and primary arthroplasty: aiming for early weightbearing. Clin Orthop Relat Res 2014;472(11):3375-3382

28 Sermon A, Broos P, Vanderschot P. Total hip replacement for acetabular fractures. Results in 121 patients operated between 1983 and 2003. Injury 2008;39(08):914-921

29 Torbert JT, Joshi M, Moraff A, et al. Current bacterial speciation and antibiotic resistance in deep infections after operative fixation of fractures. J Orthop Trauma 2015;29(01):7-17

30 Mouhsine E, Garofalo R, Borens O, et al. Acute total hip arthroplasty for acetabular fractures in the elderly: 11 patients followed for 2 years. Acta Orthop Scand 2002;73(06):615-618 